\title{
openheart Shared decision-making in selection of prosthetic aortic valve
}

\author{
Rahul Bahl
}

To cite: Bahl R. Shared decision-making in selection of prosthetic aortic valve. Open Heart 2015;2: 000269 doi:10.1136/openhrt-2015000269

Accepted 5 June 2015

\section{Linked}

http://dx.doi.org/10.1136/ openhrt-2015-000237

\section{CrossMark}

Open Heart, London, UK

Correspondence to Dr Rahul Bahl;

rahulbahl2004@hotmail.com
It is always refreshing to read research that takes into account the views and experience of patients, especially when it can aid shared decision-making. Korteland et $a l^{1}$ present a study investigating exactly this aspect in patients undergoing aortic valve replacement at three Dutch centres. Surveys were carried out in 132 patients preoperatively and 110 patients postoperatively, and focused on key areas including: experience with the decision-making process, patient preferences regarding this, and their understanding of different prosthetic valves. It is a small study, and so the findings should be seen as exploratory rather than definitive. However, there is rich data, so certain lessons can be drawn, and some of these might apply to clinical practice more generally in cardiology and cardiothoracic surgery.

Shared decision-making between patients and clinicians is desirable for a number of reasons. Certainly it is ethically important for patients to understand the relevant information about procedures that doctors propose to perform on them. This is a prerequisite for the patients to be able to give their valid consent. $^{2}$ Despite slow progress, patient surveys have consistently shown that many of them want more involvement in their care, ${ }^{3}$ and the evidence available suggests that it can improve patient knowledge, patient satisfaction and communication between doctors and patients. ${ }^{4}$ Shared decision-making is also a more satisfying form of practice for doctors themselves. Doctors frequently face uncertainty in their decisions, and this is much more easily resolved when they have come to those decisions with their patients on board.

Several factors can make shared decisionmaking a challenge. A patient's understanding of complex information may be limited. Frequently, a clinician's workload limits the amount of time available for consultations. Certain clinical situations, such as emergencies, require decisions to be made quickly and so may not allow for extended discussions. These are all common challenges in cardiology and cardiothoracic surgery.
Nevertheless, the European Society of Cardiology/European Association for Cardio-Thoracic Surgery guidelines state: 'prosthesis choice should be individualised and discussed in detail between the informed patient, cardiologists and surgeons, ${ }^{5}$ and this is echoed in the American College of Cardiology/American Heart Association guidelines: 'choice of valve intervention and prosthetic valve type should be a shared decision process'.

This study was conducted in the elective setting where time should not have been as much of an issue. It also addressed a choice where there are clear benefits and problems with both options. A metallic valve is more durable but requires lifelong anticoagulation due to its higher risk of thrombosis. This means there is a higher long-term risk of bleeding, and patients will need blood tests regularly. While a bioprosthetic valve avoids the problems of anticoagulation, it is less durable and so may necessitate reoperation if there is a problem later. We might then say that this study should represent the ideal setting for investigating communication and decision-making and cardiovascular practice.

The findings suggest that there is room for improvement. Key to this is that in the preoperative survey (which took place around 2 weeks before the operation) $68 \%$ wanted to be involved in decision-making, while only $53 \%$ felt that they were involved; $41 \%$ felt they had insufficient knowledge of valves, and $31 \%$ could not answer basic questions about choice of valve. Delving into the detail of the survey, 29 patients did not know what type of valve they were going to receive and $57 \%$ of those with bioprosthetic valves were concerned that they were going to have to use oral anticoagulation lifelong suggesting some lack of understanding. Only $64 \%$ of patients felt they had sufficient time to make a deliberate choice of valve and $36 \%$ felt that they did not have a choice at all. Interestingly, many of these same parameters were improved postoperatively which the authors partially explain by 'choice closure', 
a process by which decisions are seen as resolved and complete once they have been made. It is also certainly a factor that patient knowledge will have increased both from clinicians and from other sources between the two surveys.

Parts of the paper show where there are opportunities to improve the situation. It appears that many patients feel they need more time to make a proper decision about their choice of valve. Where possible, discussions of choice of valve could happen early to allow this. Many patients experienced significant decisional conflict, but this was significantly reduced when patients involved a friend or family member. The saying goes that 'a problem shared is a problem halved', and this is evident here. Clinics could suggest that patients bring a trusted family member or friend to consultations such as these. Finally, the authors found that patient's knowledge of valves as well as numeracy was often limited. They propose the use of decision aids to portray statistical information so that concepts of risk might be better understood. There is good evidence that decision aids can improve patient knowledge and reduce decisional conflict. $^{7}$

Some limitations to the shared decision-making approach should be acknowledged. Patients do not approach their medical consultations in the same way that medical students approach their lectures. They may understand enough information to be able to make a good decision at the time, but have no real need to retain this information once the consultation is over and a plan is in place. Some lack of specific knowledge on these surveys is therefore allowable, and does not necessarily mean that issues have been poorly communicated. The survey also shows that there are a few patients who do not want to be involved in such decisions and, presumably, would want their doctor to decide for them. While these people should generally still be given the relevant information to take a decision themselves, this is a reasonable course of action, especially in a highly specialised field. However, for the majority who want to be involved, shared decision-making carries benefits for patients and for doctors. Choice of prosthetic valve is a good setting to investigate how a clinical service is performing in this respect. Surgeons and cardiologists might be surprised by how little their patients understand of their consultations, and what their perceptions are about their care. The survey used by these authors is available for other centres to investigate their own practice and help move towards shared decision-making with their patients.

Competing interests None declared.

Provenance and peer review Commissioned; internally peer reviewed.

Open Access This is an Open Access article distributed in accordance with the Creative Commons Attribution Non Commercial (CC BY-NC 4.0) license, which permits others to distribute, remix, adapt, build upon this work noncommercially, and license their derivative works on different terms, provided the original work is properly cited and the use is non-commercial. See: http:// creativecommons.org/licenses/by-nc/4.0/

\section{REFERENCES}

1. Korteland NM, Bras FJ, van Hout FMA, et al. Prosthetic aortic valve selection: current patient experience, preferences and knowledge. Open Heart 2015;2:e000237.

2. General Medical Council. Consent: patients and doctors making decisions together. London: GMC, 2008. http://www.gmc-uk.org/ guidance/ethical_guidance/consent_guidance_index.asp

3. Coulter A, Collins A. Making shared decision-making a reality. No decision about me, without me. The King's Fund, 2011.

4. Da Silva D. Evidence: helping people share decision making, a review of evidence considering whether shared decision making is worthwhile. London: The Health Foundation, 2012.

5. Vahanian A, Alfieri O, Andreotti F, et al., The Joint Task Force on the Management of Valvular Heart Disease of the European Society of Cardiology (ESC) and the European Association for Cardio-Thoracic Surgery (EACTS). Guidelines on the management of valvular heart disease (version 2012). Eur Heart J 2012;33:2451-96.

6. Nishimura RA, Otto CM, Bonow RO, et al. 2014 AHA/ACC guideline for the management of patients with valvular heart disease: executive summary: a report of the American College of Cardiology/ American Heart Association Task Force on practice guidelines. J Am Coll Cardiol 2014;63:2438-88.

7. Stacey D, Bennett CL, Barry MJ, et al. Decision aids for people facing health treatment or screening decisions. Cochrane Database Syst Rev 2011;(10):CD001431 